\title{
Central Neurocytoma: a Case Report
}

\author{
Khaled $\mathrm{A}^{1}$, Joarder $\mathrm{MA}^{2}$, Chandy $\mathrm{M}^{3}$, Nasir TA 4
}

\begin{abstract}
Central neurocytoma is a tumour showing neuronal differentiation. This tumour usually located in ventricles occurs at young age and carries favorable prognosis. For this, accurate diagnosis is essential. There is no published case report of central neurocytoma in Bangladesh. With these objectives, we have presented a case report of central neurocytoma in a 37 years old female.
\end{abstract}

\section{Introduction}

Central neurocytoma is defined as a neoplasm composed of uniform round cells with neuronal differentiation, typically located in lateral ventricles in the region of foramen of Monroe. It affects mostly young adults and has a favorable prognosis. ${ }^{1}$

These low grade and slowly growing primary brain tumor were firstly described by Hassoun et al in $1982 .{ }^{2}$ They comprise 0.25 to $0.5 \%$ of all primary brain tumors. ${ }^{3}$ Though they are most frequently located in the lateral ventricles they can also be found in fourth ventricle 4 , Spinal cord ${ }^{5}$, cerebellum ${ }^{6}$, and pineal region. ${ }^{7}$

The majority of patients present with symptoms of increased pressure rather than with a distinct neurological deficit. The clinical history is short (mean 3.2 months). Occasionally, visual, mental disturbance and hormonal dysfunction may be observed. ${ }^{1}$

As the lesion carries a favorable prognosis, it becomes very essential that these lesions should be accurately diagnosed by surgical pathologist.

Besides, there are no published reports of central neurocytoma in this country. With this background, we have reported a clinical and histomorphological feature of central neurocytoma in a young female.

\section{Case Report}

A 37 year old nondiabetic, normotensive female presented in the neurosurgery outpatient of Apollo Hospital Dhaka with pain in the head for 1 year, as well as acute deterioration of right sided vision with diplopia for 5 days. On neurological and opthalmological examination, right lateral rectus palsy with mild pallor of both fundus was detected. No other significant neurological deficit was found. MRI Scan of brain revealed heterogeneously enhancing partly cystic mass broad based on septum pellucidum with ipsilateral ventriculomegaly. After neurosurgical decompression, the tumor tissue was sent for histopathological examination. Grossly, it was multiple small soft grey-brown pieces of tissue. Microscopically, the tumor shows proliferation of uniform small round to polygonal cells with distinct cell membrane, speckled chromatin and indistinct nucleolus (Fig 1).

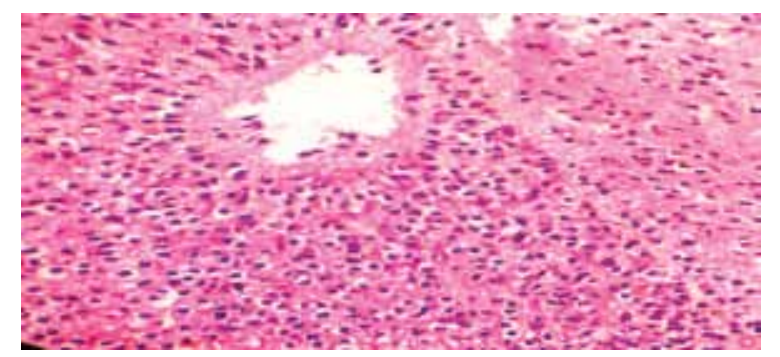

Fig 1: Proliferation of uniform round to polygonal cells with presence of perivascular pseudorossette in central neurocytoma

In some areas, these cells show peri-nuclear halo. Presence of calcification, peri-vascular pseudorossettes and small area of necrosis are also noted. After immunohistochemistry, the tumour cells show strong immunoreactivity for synaptophysin.

Based on location, histomorphology and immunohistochemical reactivity, a diagnosis of central neurocytoma was made. 


\section{Discussion}

Central neurocytoma are more frequent from 20 to 40 years of age (about $70 \%$ of the cases). It is extremely rare in children. Signs and symptoms are caused by increased intracranial pressure due to cerebro-spinal fluid block. The majority of central neurocytoma are benign though $25 \%$ of cases are more aggressive with an MIB-I labeling index $>2 \%$ and atypical histological features. These cells are strongly immunoreactive for synaptophysin. ${ }^{8}$ Based on location and histomorphology, the differential diagnosis of masses located in ventricular system, are oligodendroglioma, ependymoma and neuroblastoma. ${ }^{9}$

In light of the cellular monotony, peri-nuclear halos and frequent calcification, oligodendroglioma becomes the principal entity in the differential diagnosis. In most of the cases, these two are virtually indistinguishable at H\&E stain. Immunostaining for synaptophysin is the simplest way to distinguish neurocytoma from oligodendroglioma since the latter is nonreactive. ${ }^{9}$

Ependymoma enters into the differential diagnosis because of its paraventricular or intraventricular location and frequent calcification. Most ependymoma however, intrude unilaterally into a ventricle and also involve paraventricular tissue, where as neurocytoma lie in the midline involving the septum pellucidum and are exclusively intraventricular. The ependymoma never the less remains in the differential since the peri-vascular fibrillar zones of neurocytomas closely resemble the peri-vascular pseudorossettes of ependymoma. However, immunoreactivity of neurocytomas for synaptophysin and lack of GFAP can differentiate both. ${ }^{9}$ The cerebral neuroblastoma, a largely pediatric tumor, is intraparenchymal rather than intraventricular in location. It is also highly cellular, cytologically atypical and often shows brisk mitotic activity. Desmoplasia, necrosis, parenchymal invasion and tendency to cerebrospinal seeding further contrast neuroblastoma with histologically well differentiated appearance and macroscopic discreteness of most neurocytomas. ${ }^{9}$

The best treatment for central neurocytoma appears to be complete surgical resection. Patient with incomplete excision may benefit from radiotherapy. ${ }^{10}$

The tumor is considered of good prognosis, but a MIB-1 index higher than 2\% appears to indicate otherwise. ${ }^{11}$

\section{References:}

1. Branger DF, Kleihues P, Hassoun J. Central neurocytoma. In Kleihues $\mathrm{P}$, Cavenee WK, editors. Pathology and genetics of tumour of the nervous system. Lyon: IARC Press; 2000. p. 107-109.

2. Hassoun J, Gambarelli D, Grisoli F. Central neurocytoma: an electron microscopic study of two cases. Acta Neuropathol. 1982;56:151-156.

3. Hassoun J, Soylemezoglu F, Gambarelli D. Central neurocytoma: a synopsis of clinical and histological features. Brain Pathol. 1993;3:297-306.

4. Warmuth-Metz M, Klein R, Soransen N, Solymosi L. Central neurocytoma of the fourth ventricle: case report. J Neurosurg. 1999;91:506-509.

5. Martin AJ, Sharr MM, Teddy PJ, Gardner BP, Robinson SF. Neurocytoma of the thoracic spinal cord. Acta Neurochir. 2002;144:823-828.

6. Kapoor N, Gandhi A, Chaurasia AK. Central neurocytoma in the vermis of the cerebellum. Indian $\mathrm{J}$ Pathol Microbiol 2009;52:108-109.

7. Buccoliero AM, Caldarella A, Ammannati F, Mennonna P, Taddei A, Taddei GL. Extraventricular neurocytoma: morphological and immunohistochemistry considerations on differential diagnosis. Pathol Res Pract. 2002;198:627-633.

8. Gomes FL, Franca LR, Zymberg ST, Cavalheiro S. Central neurocytomas of uncommon location: report of two cases. Arq Neuropsiquiatr. 2006;64(4):1015-1018.

9. Burger CP, Scheithaurer WB, editors. Tumour of central nervous system: AFIP fascicles: 1994. p. 178-184.

10. Borges G, Pereira HC, Carelli EF, Fernandes YB, Bonilha L. Central neurocytoma: report of two cases. Arq Neuropsiquiatr. 2005;63(4):1084-1089.

11. Christove C, Adle-Biassette H, Le Guerinel C. Recurrent central neurocytoma with marked increase in MIB-1 labeling index. Br J Neurosurg. 1999;13:496-499. 